Article

\title{
Investigation of Strand-Selective Interaction of SNA-Modified siRNA with AGO2-MID
}

\author{
Yukiko Kamiya *D, Yuuki Takeyama, Tomonari Mizuno, Fuminori Satoh and \\ Hiroyuki Asanuma * \\ Department of Biomolecular Engineering, Graduate School of Engineering, Nagoya University, Furo-cho, \\ Chikusa-ku, Nagoya 464-8603, Japan; takeyama.yuuki@g.mbox.nagoya-u.ac.jp (Y.T.); \\ mizuno.tomonari@b.mbox.nagoya-u.ac.jp (T.M.); sato.fuminori@f.mbox.nagoya-u.ac.jp (F.S.) \\ * Correspondence: yukikok@chembio.nagoya-u.ac.jp (Y.K.); asanuma@chembio.nagoya-u.ac.jp (H.A.); \\ Tel.: +81-52-789-2552 (Y.K.); +81-52-789-2488 (H.A.)
}

Received: 28 June 2020; Accepted: 20 July 2020; Published: 23 July 2020

\begin{abstract}
Small interfering RNA (siRNA) has been recognized as a powerful gene-silencing tool. For therapeutic application, chemical modification is often required to improve the properties of siRNA, including its nuclease resistance, activity, off-target effects, and tissue distribution. Careful siRNA guide strand selection in the RNA-induced silencing complex (RISC) is important to increase the RNA interference (RNAi) activity as well as to reduce off-target effects. The passenger strand-mediated off-target activity was previously reduced and on-target activity was enhanced by substitution with acyclic artificial nucleic acid, namely serinol nucleic acid (SNA). In the present study, the reduction of off-target activity caused by the passenger strand was investigated by modifying siRNAs with SNA. The interactions of SNA-substituted mononucleotides, dinucleotides, and (2,2,6,6-tetramethylpiperidin-1-yl)oxyl (TEMPO)-labeled double-stranded RNA (dsRNA) with the MID domain of the Argonaute 2 (AGO2) protein, which plays a pivotal role in strand selection by accommodation of the $5^{\prime}$-terminus of siRNA, were comprehensively analyzed. The obtained nuclear magnetic resonance (NMR) data revealed that AGO2-MID selectively bound to the guide strand of siRNA due to the inhibitory effect of the SNA backbone located at the $5^{\prime}$ end of the passenger strand.
\end{abstract}

Keywords: siRNA; RNAi; AGO2; MID; serinol nucleic acid; off-target effect; guide strand selection; RNA; TEMPO; NMR

\section{Introduction}

Small interfering RNAs (siRNAs) are duplexes of approximately 23 base pairs composed of passenger strands and guide strands. They promote gene silencing of messenger RNA (mRNA) targets complementary to the guide strand via RNA interference (RNAi). Notably, synthetic siRNAs have shown therapeutic potential. The first siRNA drug, namely patisiran, was approved by the Food and Drug Administration (FDA) in 2018 [1]. Chemical modifications of siRNAs can improve their resistance to nuclease digestion, increase potency, and reduce off-target effects [2,3].

Translational inhibition mediated by siRNAs is executed by the RNA-induced silencing complex (RISC), which comprises a siRNA guide strand and the Argonaute 2 (AGO2) protein. During the formation of the complex, the strand with the $5^{\prime}$ end, which is involved in the thermodynamically less stable region of base pairing, is selected for loading into RISC [4]. Strand selection is critical, as base pairing between the strand loaded into RISC and the mRNA target determine the selectivity of gene silencing. However, the control of the guide strand selection only by using RNA nucleotides is insufficient; therefore, it is necessary to develop methods that would result in a reduction of off-target activity mediated by the passenger strand-incorporated RISC. Various attempts have been made to 
reduce the activity of passenger strand-incorporated RISC, even via unintended formation of the complex, or alternatively, to improve the guide strand selectivity [2,3,5-11]. Nevertheless, further developments are required to achieve precise control.

Structural studies revealed that AGO2 is composed of globular domains, i.e., N, PAZ, MID, and PIWI [12-16]. In the complex of micro RNA (miRNA) with full-length human AGO2, the $5^{\prime}$ end of miRNA is bound to the MID domain, while the $3^{\prime}$ end is bound to the PAZ domain. The seed region of miRNA is formed in an A-type helical geometry and is located in a narrow portion of the RNA binding groove of PIWI. Importantly, the 5'-terminal phosphate and nucleotide are not involved in pairing with the target mRNA. These moieties are located in a narrow binding pocket on the MID domain of AGO2 and exhibit stacking interactions and extensive hydrogen bonds with the amino acid residues of MID and PIWI. A previous study on the Y529E mutant showed that during the formation of RISC (pre-RISC), the 5'-end binding pocket of MID plays an important function in binding of miRNA to AGO2 [17]. Thus, to enhance the loading of the desired strand of siRNA into RISC, siRNAs exhibiting various $5^{\prime}$-end modifications have been proposed. For instance, introduction of metabolically stable $(E)-5^{\prime}$-vinylphosphonate [18-20] or a 5'-triazol modifier, which was developed by computational screening [21,22], at the $5^{\prime}$ end of the guide strand increased the activity of siRNA. Moreover, preventing phosphorylation of the $5^{\prime}$-hydroxyl group of the passenger strand by $\mathrm{Clp} 1$ by 5 -O-methylation or 5 -morpholino modification reduced the formation of RISC with the passenger strand [23,24]. We previously reported an acyclic nucleic acid, specifically serinol nucleic acid (SNA), which stably hybridized with RNA [25-27]. In addition, we designed SNA-substituted siRNA, in which one residue at each terminus of the passenger strand and at the $3^{\prime}$ terminus of the guide strand was substituted with SNA (Figure 1) [28]. Consequently, the passenger strand-mediated off-target activity was effectively reduced and the on-target activity was enhanced by a simple SNA substitution without any additional modification of the 5'-hydroxyl group of siRNA. We expect that the SNA-substituted siRNA design can be applied in the development of nucleic acid drugs to knock down any disease-related genes and supplement miRNA. To make this design versatile, it is necessary to elucidate the mechanisms by which the SNA substitution at the terminal positions of siRNA reduces the off-target effects. We speculated that the SNA substitution inhibits the interaction of the passenger strand with AGO2-MID due to the considerable differences between the structures of SNA and ribose, resulting in loading of the guide strand into AGO2 (Figure 1). In the present study, we focused on the interactions between AGO2-MID and SNA-modified RNAs. Specifically, we performed isothermal calorimetry (ITC) and nuclear magnetic resonance (NMR) analyses to investigate the interactions between AGO2-MID and SNA-substituted mononucleotides, dinucleotides, and (2,2,6,6-tetramethylpiperidin-1-yl)oxyl (TEMPO)-labeled double-stranded RNAs (dsRNAs). We determined that AGO2-MID asymmetrically binds to the guide strand of the SNA-modified siRNA, in which the passenger strand contains an SNA moiety at the $5^{\prime}$ end. 


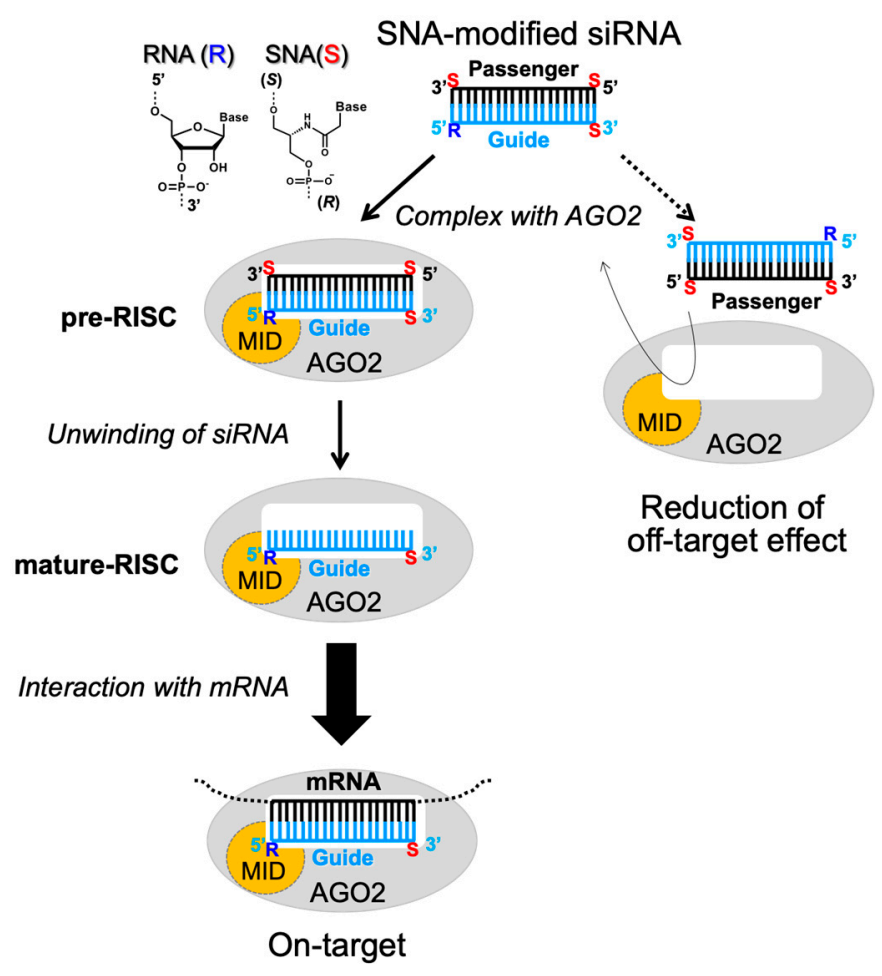

Figure 1. Schematic illustration of the proposed mechanism, by which serinol nucleic acid (SNA)-substituted small interfering RNA (siRNA) reduces off-target activity. In pre-RNA-induced silencing complex (pre-RISC), an interaction between the $5^{\prime}$ terminus of one strand and the MID domain results in selection of that strand for the formation of RISC. Off-target effects can occur if the passenger strand is selected. The presence of the SNA moiety at the $5^{\prime}$ terminus of the passenger strand inhibits the interaction with Argonaute 2 (AGO2)-MID, reducing off-target effects.

\section{Results and Discussion}

\subsection{Analyses of the Binding between AGO2-MID and Mono- and Dinucleotides}

We first analyzed the binding affinity of AGO2-MID for mono- and dinucleotides using isothermal calorimetry (ITC). The affinity of AGO2-MID for riboadenosine (A), adenosine monophosphate (AMP), SNA-A (sA), and phosphorylated SNA-A (p-sA) was compared (Figure 2 and S1 and Table 1). It was determined that although AMP bound to AGO2-MID $\left(K_{\mathrm{a}} 5.9 \times 10^{3} \mathrm{M}^{-1}\right)$, p-sA did not. The RNA dimer containing a $5^{\prime}$-phosphate group (p-rArA) exhibited approximately 40 times higher affinity for AGO2-MID than AMP. The binding constant is within the range of typical protein-nucleotide interactions. Interestingly, the 5'-phosphorylated SNA-RNA dimer (p-sArA) was recognized by AGO2-MID $\left(K_{\mathrm{a}} 7.2 \times 10^{3} \mathrm{M}^{-1}\right)$, although the binding affinity was considerably lower than that for the $5^{\prime}$-phosphorylated RNA dimer. The SNA dimer with an (S)-terminal phosphate group also bound to AGO2-MID $\left(K_{\mathrm{a}} 5.9 \times 10^{3} \mathrm{M}^{-1}\right)$, indicating that the presence of the SNA moiety at the second residue from the $5^{\prime}$ end was tolerable for interaction with AGO2-MID. On the other hand, non-phosphorylated dimers of SNA or RNA did not detectably bind to AGO2-MID (Figure S1). These data suggested that the phosphate group and the ribose backbone of the $5^{\prime}$ terminal residue of siRNA cooperatively contributed to binding to AGO2-MID, which is consistent with previous reports [12-16]. Moreover, the results indicated that even the phosphorylated SNA residue did not bind to AGO2-MID. 
(a)

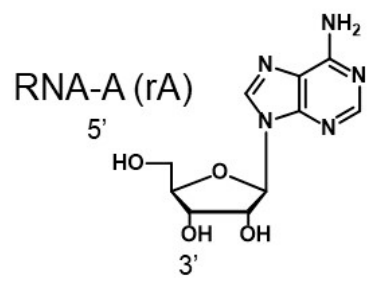<smiles></smiles>

$(R)$

(b)

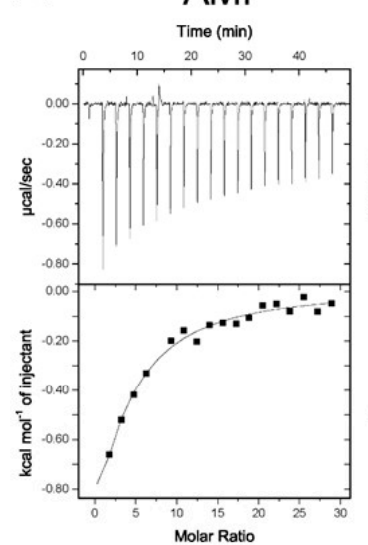

p-sAsA

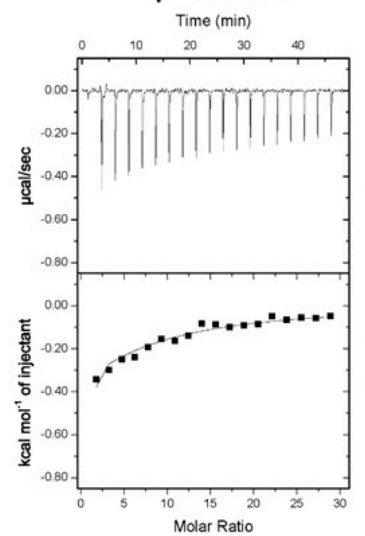

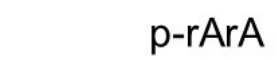

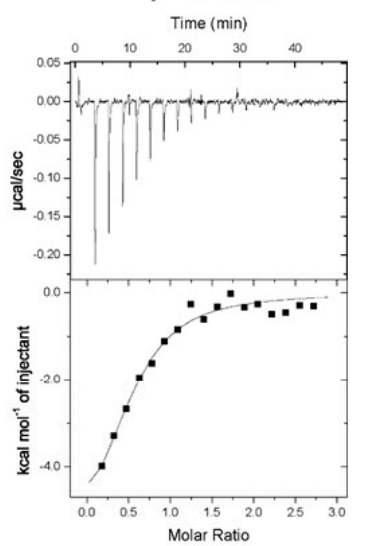

sAsA

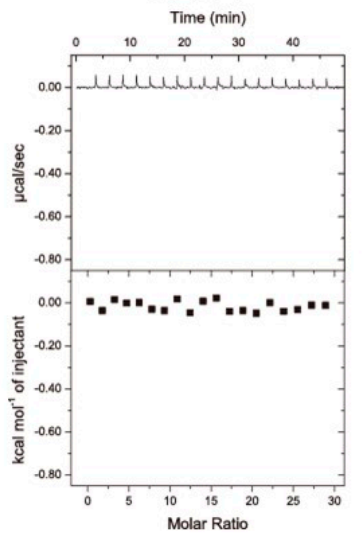

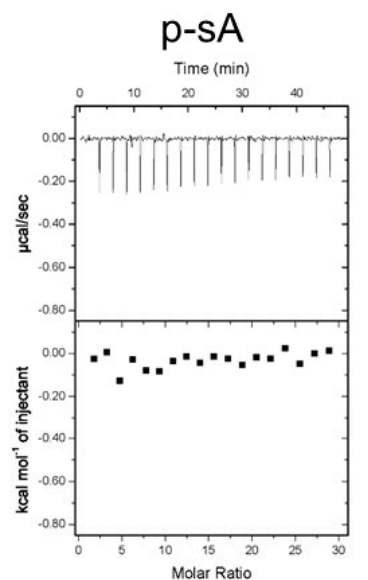

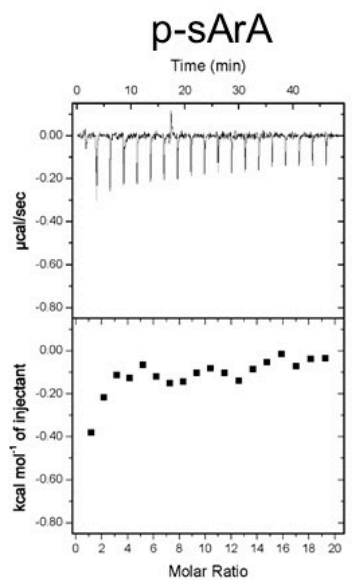

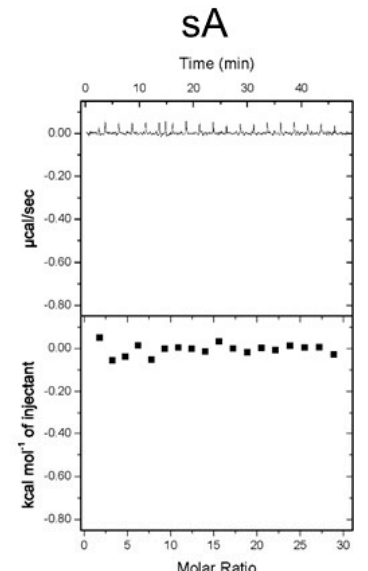

sArA

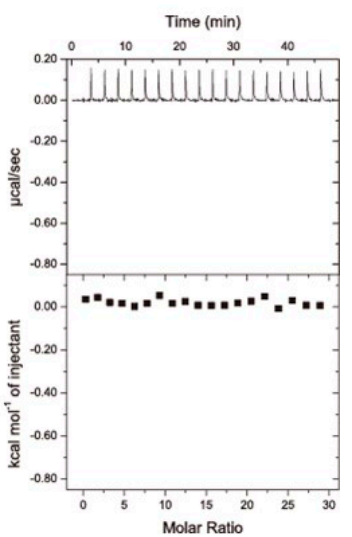

Figure 2. Isothermal calorimetry (ITC) analyses of the binding between AGO2-MID and mono- or dinucleotides. (a) Chemical structures of RNA and SNA mononucleotides. (b) ITC profiles of the binding between AGO2-MID and mono- and dinucleotides with or without terminal phosphate groups. ITC experiments were performed at $25^{\circ} \mathrm{C}$ in $25 \mathrm{mM}$ MES ( $\mathrm{pH}$ 6.5), $200 \mathrm{mM} \mathrm{NaCl}, 1 \mathrm{mM}$ tris(2-carboxyethyl)phosphine (TCEP). For each experiment, $20 \mu \mathrm{M}$ AGO2-MID was loaded into the sample cell.

Table 1. $K_{\mathrm{a}}$ values for the interaction of AGO2-MID with mono- and dinucleotides.

\begin{tabular}{|c|c|c|c|}
\hline Mononucleot(s)ide & $K_{\mathrm{a}}\left(\times 10^{3} \mathrm{M}^{-1}\right)$ & Dinucleotide & $K_{\mathrm{a}}\left(\times 10^{3} \mathrm{M}^{-1}\right)$ \\
\hline AMP & 5.9 & p-rArA & 230 \\
\hline p-sA & n.d. & p-sArA & 7.2 \\
\hline sA & n.d. & p-sAsA & 5.9 \\
\hline
\end{tabular}

AMP is adenosine monophosphate; p-sA is 5' phosphorylated SNA adenosine; rA is adenosine. n.d. indicates that binding was not detected.

We subsequently analyzed the RNAi activity and strand selectivity of SNA-modified siRNA. siRNAs modified with SNA at both $5^{\prime}$ and $3^{\prime}$ termini of the passenger strand and the $3^{\prime}$ terminus of the guide strand with and without a phosphate group at the $5^{\prime}$ end were prepared (P1s-1s/G1s-0s and 
P1s-1s/G1s-0sp, respectively; Figure 3). siRNAs modified with SNA at both termini of both strands and with a phosphate group at the $5^{\prime}$ end of the guide strand (P1s-1s/G1s-1sp) were also synthesized. Additionally, unmodified siRNA (native $\mathrm{P} / \mathrm{G}$ ) was prepared. A luciferase reporter assay was conducted to analyze the RNAi activities originating from the passenger strand and guide strand-incorporated RISC. In a previously reported assay, the pGL3-On and pGL3-Off plasmids, which were created by inserting the target sequence into the 3'-UTR of the firefly luciferase expression vector in the sense and antisense directions, respectively, were used to evaluate silencing induced by the guide and passenger strands [28]. Moreover, according to our previous study [28], both strands of the native P/G exhibited RNAi activity. Compared with unmodified siRNA, the guide strand of P1s-1s/G1s-0s, which contained an SNA residue at the 3' end, but not the 5' end, showed increased RNAi activity. In contrast, the passenger strand, in which both termini were modified with SNA, displayed reduced activity (Figure 3). Notably, P1s-1s/G1s-0sp, which had analogous SNA modifications to P1s-1s/G1s-0s and a 5'-phosphorylated guide strand, exhibited RNAi activity and guide strand selectivity equivalent to those of P1s-1s/G1s-0s (Figure 3).

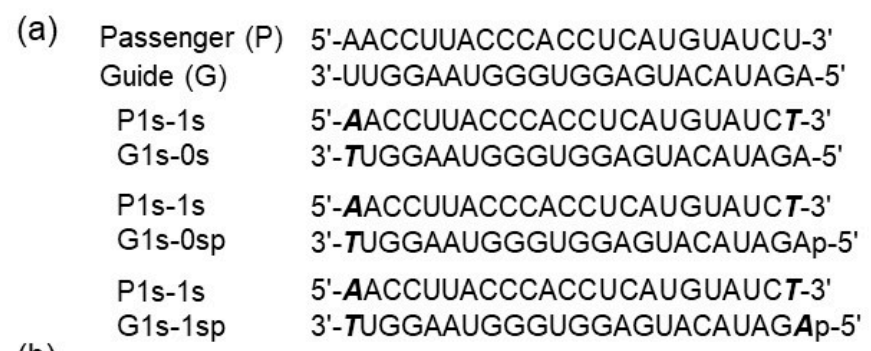

(b)

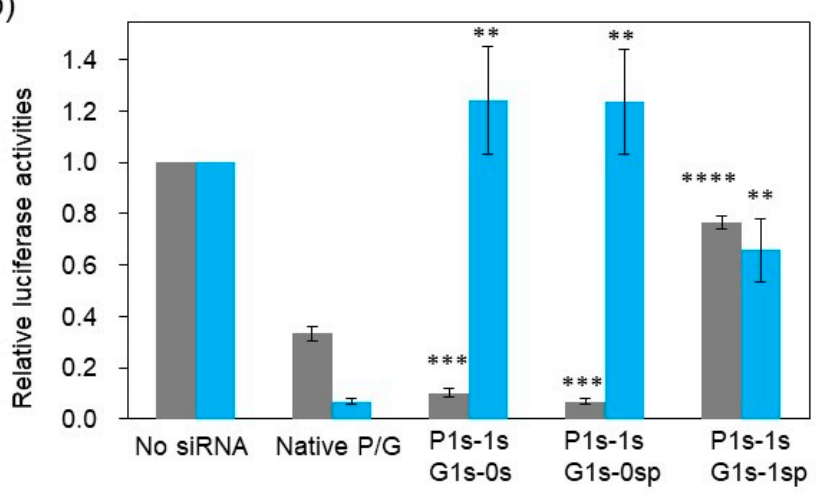

Figure 3. RNA interference (RNAi) activities of SNA-modified siRNAs. (a) siRNAs used in the luciferase assay. The upper strand is the passenger strand $(\mathrm{P})$ and the lower strand is the guide strand (G). Bold, italic characters indicate SNA and p denotes 5' phosphate. (b) RNAi activities of the guide strands (grey bars) and passenger strands (cyan bars) evaluated using reporter plasmids pGL3-On and pGL3-Off, respectively. Plotted are means and SD $(n=3)$ of firefly/Renilla luciferase signal relative to the untreated sample. ${ }^{* *} p<0.01,{ }^{* * *} p<0.001,{ }^{* * * *} p<0.0001$ vs. native $\mathrm{P} / \mathrm{G}$.

The ITC results obtained herein as well as previously reported interaction analyses indicate that the presence of a phosphate group at the $5^{\prime}$ end on of the guide strand is critical for interactions with AGO2 $[12,14,15]$. We hypothesized that the guide strand of P1s-1s/G1s-0s was 5'phosphorylated by Clp1 in cells, which enhanced the incorporation into RISC [29] and resulted in activity equivalent to that of the chemically-phosphorylated siRNA. Moreover, for P1s-1s/G1s-1sp, both passenger and guide strands of siRNA were terminally modified with SNA. In this case, little silencing activity was observed, despite the presence of the $5^{\prime}$-phosphate group on the guide strand. This suggests that incorporation of siRNA into RISC was attenuated due to the SNA backbone on the $5^{\prime}$-terminal residue of the guide strand. These data imply that a $5^{\prime}$-terminal ribose backbone is prerequisite for accommodation of siRNA in the binding pocket of AGO2-MID. 


\subsection{TEMPO Modification of RNA for NMR Analyses}

We then performed NMR analyses to obtain direct evidence of the strand selective interaction between dsRNA and AGO2-MID. To this end, the interaction between AGO2-MID and an RNA duplex modified with TEMPO was evaluated. It is known that an unpaired electron on the nitroxide group of TEMPO influences the peak intensity of NMR signals due to paramagnetic relaxation enhancement (PRE), which is related to $\mathrm{r}^{-6}$ [30]. Thus, TEMPO has been widely utilized in NMR analyses to provide long-distance information on the conformation and interactions of various biomolecules [31-35]. In this study, we attempted to evaluate the strand selectivity of AGO2-MID using a TEMPO-modified RNA duplexes.

The nitroxide radical on TEMPO is readily degraded during the detritylation and oxidation steps involved in the solid-support-based oligonucleotide synthesis $[36,37]$. TEMPO was previously effectively incorporated into RNA using optimized protocols of detritylation and oxidation in the presence of dichloroacetic acid and tert-butyl hydroperoxide, respectively [37]. Methods, in which the nitroxide group was incorporated at terminal positions of oligonucleotides for post-synthesis spin labeling of artificial ribose, nucleobase, or backbone moieties, have also been reported [38-43]. We initially attempted to prepare the TEMPO-modified oligonucleotide utilizing an amidite monomer of D-threoninol conjugated to TEMPO. Despite various modifications of the detritylation and oxidation steps during solid-phase synthesis, the nitroxide group was degraded after several cycles as a result of a reduction reaction (Figure S2a-c). Consequently, we introduced the TEMPO moiety in a post-synthetic manner. We first synthesized an amidite monomer of Fmoc-protected D-threoninol (D-thr-Fmoc) (Figure 4 and Scheme S1). Following conventional solid-phase oligonucleotide synthesis using D-thr-Fmoc, we conducted simultaneous deprotection of the Fmoc group and conjugation of TEMPO (Figure 4, step b). After the removal of RNA from controlled pore glass (CPG) and subsequent deprotection, the obtained RNAs were purified to yield TEMPO-modified RNA (Figure 4 and S2d).
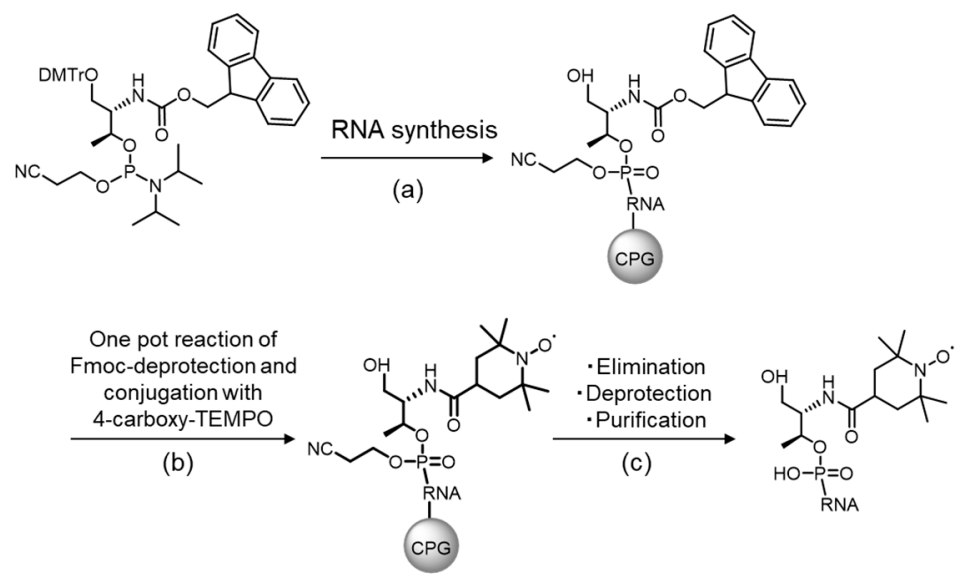

Figure 4. Scheme showing introduction of the (2,2,6,6-tetramethylpiperidin-1-yl)oxyl (TEMPO) moiety following solid-phase synthesis of RNA. (a) An Fmoc-protected D-threoninol was incorporated during solid-phase synthesis of RNA. (b) Deprotection of Fmoc and coupling of 4-carboxy-TEMPO was carried out simultaneously. RNA-conjugated controlled pore glass (CPG) was dispersed in dimethylformamide (DMF) and incubated with 4-carboxy-TEMPO (100 eq., TCI), 1-ethyl-3-(3-dimethylaminopropyl)carbodiimide (EDC) (250 eq.), hydroxybenzotriazole (HOBt) (250 eq.), and triethylamine (2.8 eq.) at $40^{\circ} \mathrm{C}$ for $12-24 \mathrm{~h}$. (c) The removal of RNA from CPG and deprotections were performed using conventional methods. The RNA was purified by reverse-phase high-performance liquid chromatography (HPLC).

\subsection{Investigation of Strand Selection by AGO2-MID}

The passenger strands were functionalized with TEMPO at either the $5^{\prime}$ or $3^{\prime}$ end and with an SNA residue at the opposite end. The obtained strands were hybridized to a guide strand modified 
with SNA at the 3' end (P1s-Te/G1s-0s and PTe-1s/G1s-0s; Figure S3). To determine whether the TEMPO-modified siRNAs were able to induce gene silencing, we performed a luciferase reporter assay. Similar to the terminally SNA-modified siRNA P1s-1s/G1s-0s, P1s-Te/G1s-0s and PTe-1s/G1s-0s showed increased guide strand activity and significantly decreased passenger strand activity compared to the native siRNA (Figure S3).

To analyze the interactions between SNA-modified siRNA mimics and AGO2-MID by NMR, we prepared two short TEMPO-modified 10-bp RNA duplexes with SNA modifications (Figure 5a). In one duplex, the passenger strand was modified with SNA at the $3^{\prime}$ end and TEMPO at the $5^{\prime}$ end (RNAa-5Te), while the guide strand was 5'-phosphorylated and modified with SNA at the $3^{\prime}$ end (RNAb). In the second duplex, the passenger strand was modified with SNA at the $5^{\prime}$ end and TEMPO at the $3^{\prime}$ end (RNAa-3Te), whereas the guide strand was RNAb. It is known that if AGO2-MID selectively interacts with the $5^{\prime}$ terminus of the guide strand, the NMR signals corresponding to AGO2-MID should be broadened upon the interaction with RNAa-3Te/RNAb due to strong PRE (Figure 5b). However, if AGO2-MID interacts with the passenger strand, the NMR signals of AGO2-MID should be broadened upon the interaction with RNAa-5Te/RNAb.
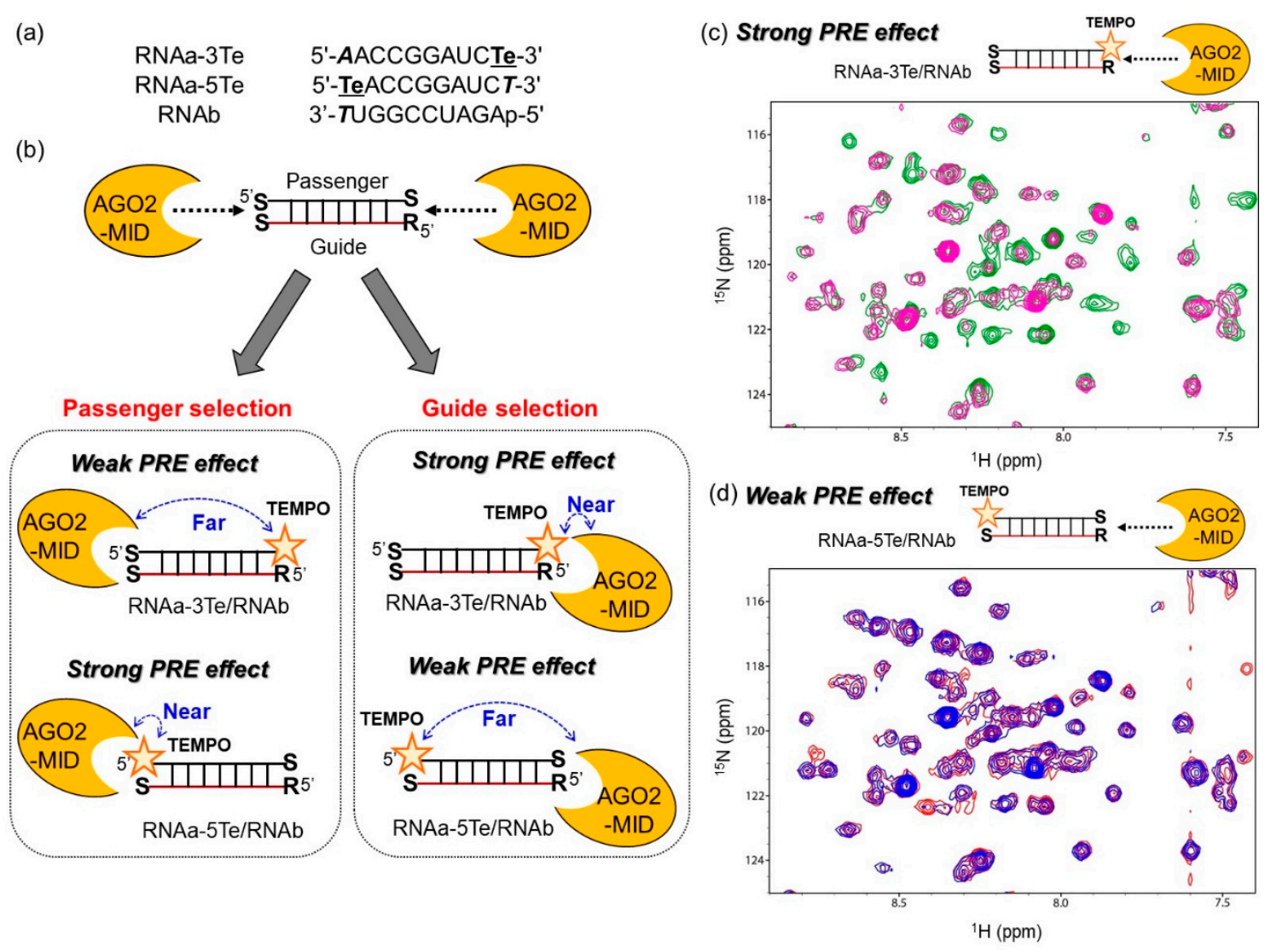

Figure 5. (a) RNAs used in the nuclear magnetic resonance (NMR) analyses. Te indicates TEMPO incorporated using a D-threoninol backbone. Bold, italic characters indicate SNA and p denotes the 5'-phosphate group. (b) Schematic illustration of the NMR analyses for investigation of strand selection by AGO2-MID. (c and d) ${ }^{1} \mathrm{H}^{-15} \mathrm{~N}$ heteronuclear single-quantum coherence (HSQC) NMR spectra of AGO2-MID (0.06 mM) with (c) RNAa-5Te/RNAb (0.4 mM) or (d) RNAa-3Te/RNAb (0.4 mM) in the absence (magenta or blue) and presence (green or red) of $2 \mathrm{mM}$ ascorbic acid.

We first compared the ${ }^{1} \mathrm{H}_{-}{ }^{15} \mathrm{~N}$ heteronuclear single-quantum coherence (HSQC) spectra of AGO2-MID with and without TEMPO-labeled RNA duplexes in the presence of ascorbic acid, which reduced the nitroxide radical. Chemical shift perturbations of several NMR signals corresponding to the AGO2-MID residues were observed when the spectrum without RNA was compared to that 
with RNA (Figure S4). Notably, the perturbed chemical shifts were consistent with those previously reported for spectra of AGO2-MID with and without UMP [11-13]. We subsequently compared the spectra of AGO2-MID complexed with TEMPO-labeled RNA in the absence and presence of ascorbic acid. While NMR signals in the ${ }^{1} \mathrm{H}_{-}{ }^{15} \mathrm{~N}$ HSQC spectra of AGO2-MID in the presence of RNAa-3Te/RNAb were considerably broadened, much less broadening was observed in the presence of RNAa-5Te/RNAb (Figure 5c,d and S5). It is noteworthy that the broadened signals disappeared in the 2D-spectra. The acquired NMR data clearly indicated that the TEMPO moiety in RNAa-3Te was located in close proximity to AGO2-MID. This conclusion was based on the observation that some of the signals attributed to AGO2-MID in the 2D spectrum of RNAa-3Te/RNAb disappeared in the absence of ascorbic acid. Moreover, the disappearance of the signals was marginal in the spectra of RNAa-5Te/RNAb, in which the TEMPO moiety was away from AGO2-MID. Thus, the obtained results revealed that AGO2-MID preferentially interacted with the $5^{\prime}$ terminus of RNAb over the $5^{\prime}$ terminus of RNAa, the residue of which was composed of an acyclic backbone.

In conclusion, we successfully synthesized TEMPO-modified RNA, enabling NMR analyses, which revealed siRNA strand selectivity of AGO2-MID. Conjugation of TEMPO after solid-phase synthesis of RNA was necessary to prevent the reduction of the nitroxide moiety. A similar strategy could be used to post-synthetically introduce a TEMPO moiety at any desired position within an oligonucleotide. Moreover, other functional groups that would be unstable under conditions used for solid-phase oligonucleotide synthesis could be also introduced using this approach.

The conducted experiments demonstrated that modification of the $5^{\prime}$ end of the passenger strand of siRNA facilitates an asymmetric interaction between AGO2-MID and siRNA, significantly enhancing the selectivity for the desired guide strand. Based on the NMR and ITC data, we concluded that the SNA substitution at the 5' end of the passenger strand considerably decreased the binding affinity of AGO2 for the passenger strand, resulting in selective incorporation of the guide strand into RISC. The outcomes of the present study provide valuable mechanistic insight into how the SNA modification at the $5^{\prime}$-terminus of the passenger strand of siRNA reduces off-target effects. The findings demonstrated herein provide a platform for further application of SNA modification in the design of therapeutic siRNAs.

\section{Materials and Methods}

\subsection{Syntheses of Dinucleotides and Oligonucleotides}

The reagents for the synthesis of the phosphoramidite monomer of Fmoc-protected D-threoninol were purchased from Tokyo Kasei Co., Ltd. (Tokyo, Japan), Wako Pure Chemical Industries, Ltd. (Osaka, Japan), and Sigma-Aldrich, (Saint Louis, MO, USA). The reagents for the oligomer syntheses and Poly Pak II cartridges were obtained from Glen Research (Sterling, VA, USA) and ChemGenes (Wilmington, MA, USA). The columns for HPLC purification were purchased from Kanto Chemical Co., Ltd (Tokyo, Japan). The RNA oligonucleotides and oligonucleotides composed of SNA and RNA were acquired from Hokkaido System Science Co., Ltd. (Sapporo, Japan).

Phosphoramidite SNA monomers were synthesized according to a previously reported method $[25,26]$. Serinol-adenine (sA) was prepared by the deprotection of the $4,4^{\prime}$-dimethoxytrityl (DMT) group in DMT-serinol-adenine using trifluoroacetic acid. Dinucleotides (sAsA, rAsA, and sArA) were synthesized using SNA phosphoramidite and RNA monomers employing the ABI-3400 DNA synthesizer (Applied Biosystems, Waltham, MA, USA). Phosphorylation of sA and dinucleotides was conducted on solid-phase using phosphorylation reagent II (Glen Research, Sterling, VA, USA). D-Threoninol-Fmoc was introduced during solid-phase synthesis. For the deprotection of Fmoc and conjugation of TEMPO, RNA-conjugated CPG was dispersed in dimethylformamide (DMF) and incubated in the presence of 4-carboxy-TEMPO (100 eq., TCI), 1-ethyl-3-(3-dimethylaminopropyl)carbodiimide (EDC) (250 eq.), hydroxybenzotriazole (HOBt) (250 eq.), and triethylamine (2.8 eq.) at $40^{\circ} \mathrm{C}$ for $12-24 \mathrm{~h}$. During this step, some elimination of RNA 
from CPG was observed; therefore, the reaction time should not be exceeded. CPG was washed with $\mathrm{DMF}$ and $\mathrm{CHCl}_{3}$ and then dried. Subsequently, the RNA oligonucleotide was removed from CPG. The deprotection was conducted by incubating the oligonucleotide with a $\mathrm{NH}_{4} \mathrm{OH} / \mathrm{EtOH}(3: 1, \mathrm{v} / \mathrm{v})$ solution at $55{ }^{\circ} \mathrm{C}$ for $8 \mathrm{~h}$. After drying under vacuum, RNA was dissolved in $1 \mathrm{M}$ tetra- $n$-butylammonium fluoride in tetrahydrofuran (THF) and stirred at $25^{\circ} \mathrm{C}$ for $24 \mathrm{~h}$ for $2^{\prime}$ deprotection. The products were purified using diethylaminoethyl cellulose (DEAE) and reverse-phase high-performance liquid chromatography (HPLC) and analyzed by electrospray ionization mass spectrometry (ESI-MS) or matrix-assisted laser desorption/ionization-time-of-flight mass spectrometry (MALDI-TOF-MS) using the Autoflex II apparatus (Bruker Daltonics, Billerica, MA, USA).

\subsection{ESI-MS Data}

p-sA Obsd. 345.085 (Calcd. for $\mathrm{C}_{10} \mathrm{H}_{3} \mathrm{~N}_{5} \mathrm{O}_{4}$ 346.0791); sA Obsd. 265.115 (Calcd. for $\mathrm{C}_{10} \mathrm{H}_{14} \mathrm{~N}_{6} \mathrm{O}_{3}$ 266.1127); p-rArA Obsd. 675.131 (Calcd. for $\mathrm{C}_{20} \mathrm{H}_{26} \mathrm{~N}_{10} \mathrm{O}_{13} \mathrm{P}_{2}$ 676.4325); p-sArA Obsd. 674.143 (Calcd. for $\mathrm{C}_{20} \mathrm{H}_{27} \mathrm{~N}_{11} \mathrm{O}_{12} \mathrm{P}_{2}$ 675.1316); p-sAsA Obsd. 673.1476 (Calcd. for $\mathrm{C}_{20} \mathrm{H}_{27} \mathrm{~N}_{12} \mathrm{O}_{11} \mathrm{P}_{2}$ 674.1403); $\mathrm{rArA}$ Obsd. 595.165 (Calcd. for $\mathrm{C}_{20} \mathrm{H}_{25} \mathrm{~N}_{10} \mathrm{O}_{10} \mathrm{P}$ 596.4538); sAsA Obsd. 593.196 (Calcd. for $\mathrm{C}_{20} \mathrm{H}_{27} \mathrm{~N}_{12} \mathrm{O}_{8} \mathrm{P}$ 594.18124); sArA Obsd. 594.180 (Calcd. for $\mathrm{C}_{20} \mathrm{H}_{26} \mathrm{~N}_{11} \mathrm{O}_{10} \mathrm{P} 595.1653$ ).

\subsection{MALDI-TOF-MS Data}

P1s-Te: Obsd. m/z 7186.66 (Calcd. for P1s-Te: $m / z$ 7187.08); PTe-1s: Obsd. m/z 7184.43 (Calcd. for PTe-1s: $m / z$ 7178.08); RNAa-5Te: Obsd. $m / z 3181.48$ (Calcd. for RNAa-5Te: $m / z$ 3175.60); RNAa-3Te: Obsd. $m / z 3192.59$ (Calcd. for RNAa-3Te: $m / z$ 3185.94).

\subsection{Protein Expression}

DNA fragment encoding human AGO2-MID (432-578) was cloned between the BamHI and SalI sites of the pCold I plasmid (Takara, Kusatsu, Japan), in which the SUMO-TEV coding region was inserted between the NdeI and BamHI sites. Hexahistidine-tagged SUMO-TEV-hAGO2-MID was expressed in the Escherichia coli BL21(DE3)pLysS strain induced with $0.5 \mathrm{mM}$ isopropyl $\beta$-D-thiogalactopyranoside. For NMR analyses, the protein was expressed in the M9 minimal medium with appropriate $\left[{ }^{15} \mathrm{~N}\right] \mathrm{NH}_{4} \mathrm{Cl}$ (Chembridge isotope laboratories Inc., Tewksbury, MA, USA)). The protein was purified using a $\mathrm{Ni}^{2+}$-NTA high-performance column (GE Healthcare, Chicago, IL, USA). The hexahistidine-modified SUMO was cleaved by incubation with proTEV (Promega, Madison, WI, USA) and further purified employing a $\mathrm{Ni}^{2+}$-NTA high-performance column and a cation exchange column (GE Healthcare, Chicago, IL, USA).

\subsection{Cell Culture}

The 293FT cells were cultured in Dulbecco's modified Eagle's medium supplemented with $10 \%$ fetal bovine serum, $80 \mu \mathrm{g} / \mathrm{mL}$ penicillin, and $90 \mu \mathrm{g} / \mathrm{mL}$ streptomycin. The cells were cultured at $37^{\circ} \mathrm{C}$ with $5 \% \mathrm{CO}_{2}$ in humidified air.

\subsection{Dual Luciferase Assay}

Reporter plasmids pGL3-On and pGL3-Off or pGlo-On and pGlo-Off were used for the dual luciferase assay $[27,28]$. The target sequence in pGL3-On and pGlo-On was 5'-AACCTTACCCAC CTCATGTATCT-3' and that in pGL3-Rv and pGlo-Off was the complementary sequence $5^{\prime}$-AGAT ACATGAGGTGGGTAAGGT-3'. The target sequences were inserted into the $3^{\prime}$-UTR region of the gene encoding firefly luciferase in pGL3. Co-transfections of the 293FT cells with siRNA (final concentrations $17 \mathrm{nM}$ ), $100 \mathrm{ng}$ of pGL3 or pGlo, and $0.5 \mathrm{ng}$ of the Renilla luciferase expression vector were performed using Lipofectamine 2000 (Invitrogen, Waltham, MA, USA) in 96-well plates according to the manufacturer's instructions. Following incubation at $37^{\circ} \mathrm{C}$ for $48 \mathrm{~h}, 75 \mu \mathrm{L}$ of the medium was removed, and $75 \mu \mathrm{L}$ of the Dual-Glo regent (Promega, Madison, WI, USA) was added. Firefly luciferase 
luminescence was measured on a Multi-label Plate Reader (EnSpire, Perkin Elmer, Waltham, MA, USA). Subsequently, $75 \mu \mathrm{L}$ of the Dual-Glo Stop \& Glo reagent was added, and the Renilla luciferase luminescence was measured.

\subsection{Calorimetric Analysis}

The ITC experiments were performed at $25{ }^{\circ} \mathrm{C}$ using the iTC200 calorimeter (GE Healthcare, Chicago, IL, USA). AGO2-MID was dialyzed against $25 \mathrm{mM}$ MES (pH 6.5), $200 \mathrm{mM} \mathrm{NaCl}$, and $1 \mathrm{mM}$ tris(2-carboxyethyl)phosphine (TCEP). $20 \mu \mathrm{M}$ AGO2-MID was first loaded into the sample cell and then $2 \mu \mathrm{L}$ of adenosine $(3 \mathrm{mM}), \operatorname{AMP}(3 \mathrm{mM}), \mathrm{sA}(3 \mathrm{mM})$, p-sA $(3 \mathrm{mM}), \operatorname{rArA}(3 \mathrm{mM}), \mathrm{p}-\mathrm{rArA}(0.3 \mathrm{mM})$, sArA $(3 \mathrm{mM})$, p-sArA $(2 \mathrm{mM})$, rAsA $(3 \mathrm{mM})$, sAsA $(3 \mathrm{mM})$, or p-sAsA $(3 \mathrm{mM})$ was added every $150 \mathrm{~s}$.

\subsection{NMR Analyses}

AGO2-MID (0.06 mM) was mixed with TEMPO-labeled RNA duplex $(0.4 \mathrm{mM})$ dissolved in $25 \mathrm{mM}$ MES ( $\mathrm{pH} 6.5), 100 \mathrm{mM} \mathrm{NaCl}$, and $10 \%(v / v) \mathrm{D}_{2} \mathrm{O}$ in the absence or presence of ascorbic acid $(2 \mathrm{mM})$. The ${ }^{1} \mathrm{H}-{ }^{15} \mathrm{~N}$ HSPQC spectra were acquired at $293 \mathrm{~K}$ using the Avance600 spectrometer equipped with a cryo-probe (Bruker BioSpin, Billerica, MA). The data were processed using the Topspin and Sparky software.

Supplementary Materials: Supplementary materials can be found at http:/www.mdpi.com/1422-0067/21/15/ 5218/s1. Figure S1: ITC analyses of binding of AGO2-MID with RNA mono and dinucleotides. Figure S2: MALDI-TOF-MS analyses of crude DNA or RNA oligomers containing D-threoninol-conjugated TEMPO. Figure S3: RNAi activities of TEMPO- and SNA-modified siRNAs. Figure S4: 1H-15N HSQC spectra of AGO2-MID complexed with RNA. Figure S5: 1H-15N HSQC spectra of AGO2-MID complexed with TEMPO-RNA in the absence or presence of ascorbic acid. Scheme S1: Synthesis of phosphoramidite monomer of Fmoc-conjugated D-threoninol.

Author Contributions: Conceptualization, Y.K.; methodology, Y.K.; preparation of protein and oligonucleotides, Y.K., Y.T., T.M., and F.S.; Luciferase, ITC and NMR analyses, Y.K., Y.T., and T.M.; writing—original draft preparation, Y.K.; writing - review and editing, Y.K. and H.A.; visualization, Y.K. funding acquisition, Y.K. and H.A. All authors have read and agreed to the published version of the manuscript.

Funding: This research was funded in part by the Grants-in-Aid for Scientific Research (Grant Numbers 20K05745 to Y.K.) and AMED (Grant Number 19 am0401007 to H.A.).

Acknowledgments: We thank Yuichiro Aiba (Nagoya University) for providing the SUMO-TEV plasmid and Takashi Tenno (Nagoya University) for his help in NMR measurements. The authors wish to acknowledge the Division for Medical Research Engineering, Nagoya University Graduate School of Medicine for allowing use of the iTC200 calorimeter.

Conflicts of Interest: The authors declare no conflict of interest.

\section{Abbreviations}

$\begin{array}{ll}\text { SiRNA } & \text { Small interfering RNA } \\ \text { AGO } & \text { Argonaute } \\ \text { RISC } & \text { RNA-induced silencing complex } \\ \text { NMR } & \text { nuclear magnetic resonance } \\ \text { TEMPO } & \text { 2,2,6,6-tetramethylpiperidine 1-oxyl } \\ \text { SNA } & \text { Serinol nucleic acid } \\ \text { RISC } & \text { RNA-induced silencing complex } \\ \text { RNAi } & \text { RNA interference } \\ \text { AMP } & \text { Adenosine monophosphate } \\ \text { TCEP } & \text { Tris(2-carboxyethyl)phosphine hydrochloride } \\ \text { ITC } & \text { Isothermal titration calorimetry } \\ \text { PRE } & \text { paramagnetic relaxation enhancement } \\ \text { HSQC } & \text { heteronuclear single-quantum coherence }\end{array}$




\section{References}

1. Adams, D.; Gonzalez-Duarte, A.; O’Riordan, W.D.; Yang, C.C.; Ueda, M.; Kristen, A.V.; Tournev, I.; Schmidt, H.H.; Coelho, T.; Berk, J.L.; et al. Patisiran, an RNAi Therapeutic, for Hereditary Transthyretin Amyloidosis. N. Engl. J. Med. 2018, 379, 11-21. [CrossRef] [PubMed]

2. Khvorova, A.; Watts, J.K. The chemical evolution of oligonucleotide therapies of clinical utility. Nat. Biotechnol. 2017, 35, 238-248. [CrossRef] [PubMed]

3. Shen, X.; Corey, D.R. Chemistry, mechanism and clinical status of antisense oligonucleotides and duplex RNAs. Nucleic Acids Res. 2018, 46, 1584-1600. [CrossRef] [PubMed]

4. Schwarz, D.S.; Hutvagner, G.; Du, T.; Xu, Z.; Aronin, N.; Zamore, P.D. Asymmetry in the assembly of the RNAi enzyme complex. Cell 2003, 115, 199-208. [CrossRef]

5. Vaish, N.; Chen, F.; Seth, S.; Fosnaugh, K.; Liu, Y.; Adami, R.; Brown, T.; Chen, Y.; Harvie, P.; Johns, R.; et al. Improved specificity of gene silencing by siRNAs containing unlocked nucleobase analogs. Nucleic Acids Res. 2011, 39, 1823-1832. [CrossRef]

6. Snead, N.M.; Escamilla-Powers, J.R.; Rossi, J.J.; McCaffrey, A.P. 5' Unlocked Nucleic Acid Modification Improves siRNA Targeting. Mol. Ther. Nucleic Acids 2013, 2, e103. [CrossRef]

7. Amarzguioui, M.; Holen, T.; Babaie, E.; Prydz, H. Tolerance for mutations and chemical modifications in a siRNA. Nucleic Acids Res. 2003, 31, 589-595. [CrossRef]

8. Chiu, Y.L.; Rana, T.M. siRNA function in RNAi: A chemical modification analysis. RNA 2003, 9, 1034-1048. [CrossRef]

9. Watts, J.K.; Choubdar, N.; Sadalapure, K.; Robert, F.; Wahba, A.S.; Pelletier, J.; Pinto, B.M.; Damha, M.J. 2'-fluoro-4'-thioarabino-modified oligonucleotides: Conformational switches linked to siRNA activity. Nucleic Acids Res. 2007, 35, 1441-1451. [CrossRef]

10. Takahashi, M.; Nagai, C.; Hatakeyama, H.; Minakawa, N.; Harashima, H.; Matsuda, A. Intracellular stability of 2'-OMe-4'-thioribonucleoside modified siRNA leads to long-term RNAi effect. Nucleic Acids Res. 2012, 40, 5787-5793. [CrossRef]

11. Deleavey, G.F.; Frank, F.; Hassler, M.; Wisnovsky, S.; Nagar, B.; Damha, M.J. The 5' binding MID domain of human Argonaute2 tolerates chemically modified nucleotide analogues. Nucleic Acid Ther. 2013, 23, 81-87. [CrossRef] [PubMed]

12. Frank, F.; Sonenberg, N.; Nagar, B. Structural basis for 5'-nucleotide base-specific recognition of guide RNA by human AGO2. Nature 2010, 465, 818-822. [CrossRef] [PubMed]

13. Frank, F.; Fabian, M.R.; Stepinski, J.; Jemielity, J.; Darzynkiewicz, E.; Sonenberg, N.; Nagar, B. Structural analysis of 5'-mRNA-cap interactions with the human AGO2 MID domain. EMBO Rep. 2011, 12, 415-420. [CrossRef]

14. Schirle, N.T.; MacRae, I.J. The crystal structure of human Argonaute2. Science 2012, 336, 1037-1040. [CrossRef]

15. Elkayam, E.; Kuhn, C.D.; Tocilj, A.; Haase, A.D.; Greene, E.M.; Hannon, G.J.; Joshua-Tor, L. The structure of human argonaute-2 in complex with miR-20a. Cell 2012, 150, 100-110. [CrossRef] [PubMed]

16. Schirle, N.T.; Sheu-Gruttadauria, J.; MacRae, I.J. Structural basis for microRNA targeting. Science 2014, 346, 608-613. [CrossRef]

17. Rüdel, S.; Wang, Y.; Lenobel, R.; Körner, R.; Hsiao, H.H.; Urlaub, H.; Patel, D.; Meister, G. Phosphorylation of human Argonaute proteins affects small RNA binding. Nucleic Acids Res. 2011, 39, 2330-2343. [CrossRef]

18. Prakash, T.P.; Lima, W.F.; Murray, H.M.; Li, W.; Kinberger, G.A.; Chappell, A.E.; Gaus, H.; Seth, P.P.; Bhat, B.; Crooke, S.T.; et al. Identification of metabolically stable $5^{\prime}$-phosphate analogs that support single-stranded siRNA activity. Nucleic Acids Res. 2015, 43, 2993-3011. [CrossRef]

19. Elkayam, E.; Parmar, R.; Brown, C.R.; Willoughby, J.L.; Theile, C.S.; Manoharan, M.; Joshua-Tor, L. siRNA carrying an (E)-vinylphosphonate moiety at the 5 end of the guide strand augments gene silencing by enhanced binding to human Argonaute-2. Nucleic Acids Res. 2017, 45, 3528-3536. [CrossRef]

20. Schirle, N.T.; Kinberger, G.A.; Murray, H.F.; Lima, W.F.; Prakash, T.P.; MacRae, I.J. Structural Analysis of Human Argonaute-2 Bound to a Modified siRNA Guide. J. Am. Chem. Soc. 2016, 138, 8694-8697. [CrossRef]

21. Onizuka, K.; Harrison, J.G.; Ball-Jones, A.A.; Ibarra-Soza, J.M.; Zheng, Y.; Ly, D.; Lam, W.; Mac, S.; Tantillo, D.J.; Beal, P.A. Short interfering RNA guide strand modifiers from computational screening. J. Am. Chem. Soc. 2013, 135, 17069-17077. [CrossRef] [PubMed] 
22. Suter, S.R.; Sheu-Gruttadauria, J.; Schirle, N.T.; Valenzuela, R.; Ball-Jones, A.A.; Onizuka, K.; MacRae, I.J.; Beal, P.A. Structure-Guided Control of siRNA Off-Target Effects. J. Am. Chem. Soc. 2016, 138, 8667-8669. [CrossRef] [PubMed]

23. Chen, P.Y.; Weinmann, L.; Gaidatzis, D.; Pei, Y.; Zavolan, M.; Tuschl, T.; Meister, G. Strand-specific 5'-O-methylation of siRNA duplexes controls guide strand selection and targeting specificity. RNA 2008, 14, 263-274. [CrossRef] [PubMed]

24. Kumar, P.; Parmar, R.G.; Brown, C.R.; Willoughby, J.L.S.; Foster, D.J.; Babu, I.R.; Schofield, S.; Jadhav, V.; Charisse, K.; Nair, J.K.; et al. 5'-Morpholino modification of the sense strand of an siRNA makes it a more effective passenger. Chem. Commun. 2019, 55, 5139-5142. [CrossRef]

25. Kashida, H.; Murayama, K.; Toda, T.; Asanuma, H. Control of the chirality and helicity of oligomers of serinol nucleic acid (SNA) by sequence design. Angew. Chem. 2011, 50, 1285-1288. [CrossRef]

26. Murayama, K.; Tanaka, Y.; Toda, T.; Kashida, H.; Asanuma, H. Highly stable duplex formation by artificial nucleic acids acyclic threoninol nucleic acid (aTNA) and serinol nucleic acid (SNA) with acyclic scaffolds. Chem. Eur. J. 2013, 19, 14151-14158. [CrossRef]

27. Kamiya, Y.; Donoshita, Y.; Kamimoto, H.; Murayama, K.; Ariyoshi, J.; Asanuma, H. Introduction of 2,6-Diaminopurines into Serinol Nucleic Acid Improves Anti-miRNA Performance. ChemBioChem 2017, 18, 1917-1922. [CrossRef]

28. Kamiya, Y.; Takai, J.; Ito, H.; Murayama, K.; Kashida, H.; Asanuma, H. Enhancement of stability and activity of siRNA by terminal substitution with serinol nucleic acid (SNA). ChemBioChem 2014, 15, 2549-2555. [CrossRef]

29. Weitzer, S.; Martinez, J. The human RNA kinase hClp1 is active on 3' transfer RNA exons and short interfering RNAs. Nature 2007, 447, 222-226. [CrossRef]

30. Kosen, P.A. Spin labeling of proteins. Methods Enzymol. 1989, 177, 86-121.

31. Ramos, A.; Varani, G. A new method to detect long-range protein-RNA contacts: NMR detection of electron-proton relaxation induced by nitroxide spin-labeled RNA. J. Am. Chem. Soc. 1998, 120, 10992-10993. [CrossRef]

32. Liu, S.; Venot, A.; Meng, L.; Tian, F.; Moremen, K.W.; Boons, G.J.; Prestegard, J.H. Spin-labeled analogs of CMP-NeuAc as NMR probes of the alpha-2,6-sialyltransferase ST6Gal I. Chem. Biol. 2007, 14, 409-418. [CrossRef] [PubMed]

33. Su, X.C.; Otting, G. Paramagnetic labelling of proteins and oligonucleotides for NMR. J. Biomol. NMR 2010, 46, 101-112. [CrossRef]

34. Yagi-Utsumi, M.; Kameda, T.; Yamaguchi, Y.; Kato, K. NMR characterization of the interactions between lyso-GM1 aqueous micelles and amyloid beta. FEBS Lett. 2010, 584, 831-836. [CrossRef] [PubMed]

35. Jahnke, W. Spin labels as a tool to identify and characterize protein-ligand interactions by NMR spectroscopy. ChemBioChem 2002, 3, 167-173. [CrossRef]

36. Rozantsev, E.G.; Sholle, V.D. Synthesis and Reactions of Stable Nitroxyl Radicals I. Synthesis. Synthesis 1971, 4, 190-202. [CrossRef]

37. Shelke, S.A.; Sigurdsson, S.T. Site-Directed Spin Labelling of Nucleic Acids. Eur. J. Org. Chem. 2012, 2012, 2291-2301. [CrossRef]

38. Edwards, T.E.; Okonogi, T.M.; Robinson, B.H.; Sigurdsson, S.T. Site-specific incorporation of nitroxide spin-labels into internal sites of the TAR RNA; structure-dependent dynamics of RNA by EPR spectroscopy. J. Am. Chem. Soc. 2001, 123, 1527-1528. [CrossRef]

39. Ding, P.; Wunnicke, D.; Steinhoff, H.J.; Seela, F. Site-directed spin-labeling of DNA by the azide-alkyne 'click' reaction: Nanometer distance measurements on 7-deaza-2'-deoxyadenosine and 2'-deoxyuridine nitroxide conjugates spatially separated or linked to a 'dA-dT' base pair. Chem. Eur. J. 2010, 16, 14385-14396. [CrossRef]

40. Weinrich, T.; Jaumann, E.A.; Scheffer, U.; Prisner, T.F.; Gobel, M.W. A Cytidine Phosphoramidite with Protected Nitroxide Spin Label: Synthesis of a Full-Length TAR RNA and Investigation by In-Line Probing and EPR Spectroscopy. Chem. Eur. J. 2018, 24, 6202-6207. [CrossRef]

41. Kerzhner, M.; Matsuoka, H.; Wuebben, C.; Famulok, M.; Schiemann, O. High-Yield Spin Labeling of Long RNAs for Electron Paramagnetic Resonance Spectroscopy. Biochemistry 2018, 57, 2923-2931. [CrossRef] [PubMed] 
42. Shepherd, N.E.; Gamsjaegera, R.; Vandevenne, M.; Cubeddua, L.; Mackay, J.P. Site directed nitroxide spin labeling of oligonucleotides for NMR and EPR studies. Tetrahedron 2015, 71, 813-819. [CrossRef]

43. Wunderlich, C.H.; Huber, R.G.; Spitzer, R.; Liedl, K.R.; Kloiber, K.; Kreutz, C. A novel paramagnetic relaxation enhancement tag for nucleic acids: A tool to study structure and dynamics of RNA. ACS Chem. Biol. 2013, 8 , 2697-2706. [CrossRef] [PubMed]

(C) 2020 by the authors. Licensee MDPI, Basel, Switzerland. This article is an open access article distributed under the terms and conditions of the Creative Commons Attribution (CC BY) license (http://creativecommons.org/licenses/by/4.0/). 